\title{
Vozes tuteladas, cidadanias esquivas: imagens discursivas de crianças e adolescentes no Brasil e na Colômbia*
}

\author{
Maria del Carmen Castrillón Valderrutén ${ }^{\prime}$ \\ Universidad Nacional de Rosario
}

\section{Resumo}

Este trabalho destaca marcas discursivas nas vozes de crianças e adolescentes em condições de tutela pública no Brasil e na Colômbia, considerando que elas estão atravessadas pelas trajetórias institucionais de proteção em ambos os países, nas quais se destacam diferenças sociojurídicas importantes. A questão central é pensar se tais trajetórias contextuais produzem efeitos diferenciados nas discursividades que as próprias crianças e os adolescentes participantes desta pesquisa constroem sobre sua condição social e identitária de tutelados. Assim, levou-se a cabo, no Brasil e na Colômbia, um conjunto de oficinas temáticas e grupos focais com algumas crianças e adolescentes de instituições de abrigamento e de outros programas de proteção. A discussão traz à baila um conflito de discursos sobre ser criança ou adolescente tutelado, em que uma lógica da cidadania confronta-se com uma enraizada lógica da menoridade, com sua cruel compaixão e repressão.

Palavras-chave: Crianças e adolescentes tutelados; lógica de menoridade; direitos cidadãos; circularidade institucional.

\footnotetext{
Abstract

This study aims to highlight some marks in the discursive images of children and adolescents in terms of public protection in Brazil and Colombia.

- Guardianship voices, elusive citizenships: discursive images of children and adolescents in Brazil and Colombia

${ }^{1}$ Artigo escrito com base no trabalho etnográfico realizado no Brasil e na Colômbia como parte da tese de doutorado em Antropologia Social, defendida em 2005, no Centro de Pesquisa e Pósgraduação sobre as Américas-CEPPAC/Universidade de Brasilia, Brasil. Endereço para correspondências: Cra. 4 Norte, 67n-03, B, Calima, Santiago de Cali, Valle Del Cauca, Colombia (carmencastri@gmail.com).
} 
Considering that these voices are trespassed by trajectories of institutional guardianship in both countries it is drawn attention to important sociallaw differences that situates Brazil as a pioneer inside Latin America when regarding the approval of an integral protection statute for children and adolescents (ECA/1990); Colombia has recently approved similar law (Lei 1098 del 2006, existing since May 2007). The central question to put forward is whether such contextual trajectories produce different effects in the discourses that children and adolescents who participate of this research build over their social condition and guardianship identity. Thus, equally in Brazil as in Colombia, it took place thematic workshops and focal groups with a number of children and adolescents from guardian institutions and other protection programs. The discussion suggests conflicts of discourses about being a child/adolescent under protection, in which a citizenship logic face up an entrenched minority logic in its cruel compassion/repression.

Keywords: Children and adolescents under guardianship; minority logic; citizen rights; institutional circularity.

Descubrir a los niños significa, en última instancia, darse cuenta de su relativa autonomía. En otras palabras, se debe descubrir que los niños no son simplemente adultos pequeños. Se van haciendo adultos individualmente a lo largo de un proceso civilizador social que varia de acuerdo con el estado de desarrollo de los respectivos modelos sociales de civilización. (NORBERTO ELIAS, 1998)

\section{Por uma consideração protagônica de vozes menorizadas}

G mbora o conjunto de crianças e adolescentes que dão sentido às idéias deste artigo seja uma pequena fração do imenso universo da infância e adolescência institucionalizadas no Brasil e na Colômbia, constitui um grupo profundamente significativo, a respeito dos traços da vida social expressos em palavras, imagens e eventos. Eles deixam em cena sentimentos individuais 
Vozes tuteladas, cidadanias esquivas: imagens discursivas de crianças e adolescentes... María del Carmen Castrillón Valderrutén

de incerteza frente a seu presente e futuro e também claridades acerca de quem são e quem desejam ser, ou seja, reconhecem, desde sua trajetória de vida marcada por experiências de tutela pública, os lugares sociais e morais onde estão como forma de sobrevivência.

Com o intuito de me aproximar dessas discursividades, levei a cabo no Brasil (Brasília) e na Colômbia (Santiago de Cali) um conjunto de oficinas temáticas e grupos focais com algumas crianças e adolescentes de instituições de abrigo e de outros programas de proteção, no percurso de campo realizado entre março de 2002 e maio de 2003 - da tese de doutorado em Antropologia. Adiscussão apóia-se em alguns fragmentos discursivos, traz à baila um conflito sobre ser criança ou adolescente tutelado, em que uma lógica da cidadania confronta-se com uma enraizada lógica da menoridade, com sua cruel compaixão e repressão.

Tentei percorrer alguns traços dessas vidas, a partir das próprias vozes das crianças e dos adolescentes com quem construí esta experiência etnográfica, destacando as formas como eles significam a infância, adolescência e seus direitos, desde seus contextos de institucionalização e tutela. É fundamental salientar que essas vozes, sendo sociais, estão inseridas no que Bakhtin (1981) chamou de "polifonia", a analisar o caráter autoral coletivo dentro da relação discurso-sujeito, e que, no âmbito desta reflexão, remeteria à idéia de que o que foi expresso por cada uma das crianças e dos adolescentes não pertence unicamente a eles, pois, em suas falas e imagens, ecoam simultaneamente outras vozes, distantes, próximas e até imperceptíveis. São as vozes dos espaços institucionais que cotidianamente os situam como tutelados e, de modo geral, as vozes da história política, cultural e econômica que os nomeia como crianças, adolescentes ou menores.

Tradicionalmente, crianças e adolescentes têm ocupado lugares implícitos no grande espectro cognitivo das ciências sociais, de forma que o que é pensado e dito sobre essas duas categorias e grupos sociais já vem inscrito e explicado nas reflexões de outras categorias, grupos sociais e eventos - família, parentesco, religião, educação, gênero, arte etc. - para dar conta do mundo da vida adulta (BRANDÃO, 1985; CASTRILLÓN, 2005).

Apenas recentemente crianças e adolescentes vêm adquirindo estatutos acadêmicos e conceituais mais sistemáticos, nos diversos campos das ciências sociais, reforçados pela circulação de debates e interpelações no campo jurídico-político, no que diz respeito aos direitos humanos e à cidadania deles. 


\section{HUMANAS}

Começa-se a reconceituar seus lugares históricos, outorgando-se-lhes, desse modo, a condição de sujeitos ativos que, como os adultos, também produzem e significam, mediante discursividades e práticas, as tramas sociais, políticas e culturais que dão sentido a suas trajetórias de vida(CORSARO, 1997; CORSARO e EDER, 1990; JAMES, JENKS e PROUT, 1998; SARMENTO, 2002; JAVEAU, 2005, LOPES DA SILVA, MACEDO e NUNES, 2002; CASTRO, 2001; GRAUE e WALSH, 2003; COHN, 2005, dentre outros). ${ }^{2}$

Essas novas maneiras de se entender a infância e a adolescência têm como ponto comum de partida uma crítica às perspectivas funcionalistas $\mathrm{e}$ evolucionistas das relações sociais e, particularmente, uma revisão da categoria de socialização, que subsumiu historicamente as singularidades de crianças e adolescentes, na compreensão das formas adultas de constituição social, tornando essas "idades da vida" etapas transitórias e pré-lógicas. Ao contrário, essas "idades da vida", como categorias para pensar a vida social, são inscritas no que Corsaro e Eder (1990, p. 199-200) denominam "perspectiva interpretativa". Nessa visão, as crianças são compreendidas nos laços sociais, interatuando e negociando com outros, redefinindo então a noção de "estágios", pois se trata de perceber o desenvolvimento como um denso "processo produtivo-reprodutivo", que reorganiza o conhecimento que as próprias crianças têm de si e dos outros e que se modifica na mão de seu desenvolvimento cognitivo e de suas habilidades de linguagem, ambos estruturados em seus mundos sociais.

Desde essa perspectiva, Sarmento (2002, p.2) oferece uma idéia importante acerca da tradição epistemológica moderna com relação ao imaginário infantil (que em termos de incompletude pode se estender à adolescência). $O$ autor afirma que esse imaginário se concebe como expressão de um déficit, já que as crianças - na epistemologia funcionalista e evolucionista carecem de um mundo objetivo e racional, que tenha, portanto, vínculos imperfeitos com a realidade. $O$ autor afirma que é na ordem da diferença,

\footnotetext{
2 Outra questão a ser salientada é que as perspectivas teórico-empíricas hegemônicas sobre a infância e a adolescência têm sido amplamente construídas em epicentros europeus e anglosaxð̃es, influenciando significativamente as reflexð̃es latino-americanas. Autores como Ariès (1987), Donzelot (1986), DeMause (1982) e Mead $(1977,1978,1993)$ são referências vitais em nossas compreensões sobre a vida social da infância e da adolescência. Contudo, o desafio ainda é pensar de forma sistemática e densa como emergem e se debruçam as "idades da vida" em nossas maneiras de viver os processos civilizatórios da modernidade ocidental, tendo-se em conta um arcabouço teórico mais local e regional.
} 
Vozes tuteladas, cidadanias esquivas: imagens discursivas de crianças e adolescentes... Maria del Carmen Castrillón Valderrutén

e não do déficit que se deve pensar o imaginário e a vida social das crianças, ou seja, no âmbito das singularidades em jogo e da participação protagônica na cultura que as (des)legitima.

Uma interpretação do caráter polifônico das narrativas institucionais dessas crianças e adolescentes abre o leque de sentidos políticos e socioculturais outorgados às medidas protetivas e assistenciais que 0 Estado exerce em suas diversas instâncias. São múltiplas e complexas as marcas discursivas construídas nessas vozes cercadas pela tutela pública, que são ao mesmo tempo estruturadas e estruturantes de formas orgânicas de explicação dos mundos sociais nos quais eles estão inseridos. Vale a pena referenciar Geertz $(2000$, p. 211$)$ que, ao refletir sobre as recentes formas como os pesquisadores da cultura incorporam o conhecimento da mente, das emoções e dos sentimentos, sublinha a emergência de uma concepção da "mente infantil" seriamente revisada em diversas áreas de estudo, como a antropologia, a lingüística, a psicologia do desenvolvimento. Essa concepção, aliás, concepções da "mente infantil", que também podem fornecer críticas às visões funcionalistas de o que se poderia chamar "mente adolescente", reivindicam o princípio de que essas (mentes) constroem, buscam, preservam e usam significados de modelos de sociedade, dos outros, da natureza, do pensamento, do eu, dos sentimentos etc. Enfim, trata-se de assumir crianças e adolescentes em termos de singularidade relacional, e não de incompletude, pois eles também constroem formas orgânicas de explicação do mundo legitimamente instituídas. Eles posicionam suas interpretações sobre a complexa relação entre natureza e cultura, relação que, desde os olhares adultocêntricos, confina essas crianças e adolescentes unicamente na ordem da natureza, que é representada e significada numa dimensão de incivilidade.

Em se tratando de crianças e adolescentes em condições de tutela pública, a singularidade relacional dá-se no complexo institucional que se sustenta naquilo que pode ser chamado de lógica da menoridade, enquanto constitui uma corporeidade sociojurídica que transcende os limites civis das idades, para ordenar e classificar na ordem da moral crianças e adolescentes no bojo da dicotomia normalanormal, e que perdura ainda em contextos como o brasileiro, que constroem uma tradição jurídica de forte visibilidade dos direitos cidadãos de crianças e adolescentes na América Latina (CASTRILLÓN, 2009). 


\section{HUMANANAS}

Como afirma Vianna (1999, p. 167-190), na esteira do conceito de "poder tutelar" de Lima ${ }^{3}$, o "processo simbólico de substancialização da menoridade" é mais do que um mecanismo civil de estatuto etário, pois constitui uma "relação de dominação e hierarquia" frente à consecução de direitos formais, fixando classificações sobre o vínculo social da população dentro de um mesmo território político nacional. Nessa perspectiva, é preciso acrescentar que essas classificações possíveis são atravessadas por categorias e hierarquias de gênero, etnia, classe social, origem territorial, dentre outras.

\section{Os lugares da vida institucional de crianças e adolescentes}

São variadas as experiências institucionais de cada criança e adolescente participante desta pesquisa e elas dependem profundamente da experiência definidora de vulneração de seus direitos (abuso e exploração sexuais, trabalho infantil, orfandade etc. e suas múltiplas combinações perversas) e da forma como intervêm nelas os programas e serviços sociais (abrigos, familias substitutas, casas-lares), a partir de enquadramentos legislativos contemplados tanto no Estatuto da Criança e do Adolescente (ECA-BRASIL, 1990) do Brasil como no Código del Menor, da Colômbia, que vigorava na época da pesquisa. Esse código foi substituído pelo Código de La Infancia y de La Adolescencia (Lei 1.098, de 2006), aprovado em maio de 2007 e que, assim como o ECA, fundamenta-se e estrutura-se no Paradigma da Proteção Integral que, segundo a Convenção Internacional sobre os Direitos da Criança (ONU, 1989), projeta legislativamente crianças e adolescentes como sujeitos de direitos, incorporando status jurídico dentro de uma lógica dos direitos cidadãos, e não dentro de uma lógica da menoridade.

São diversificados os lugares ou espaços institucionais onde vivem tais crianças e adolescentes com quem construí esta experiência etnográfica. As crianças e adolescentes de Brasília pertencem a duas instituições de abrigo: uma que trabalha na modalidade casas-lares, onde estão sob o cuidado de mães sociais; e outra que abriga fundamentalmente crianças e adolescentes de sexo masculino que viveram nas ruas, os quais, num único espaço,

\footnotetext{
${ }^{3}$ Lima (1995, p.73-76) salienta que esse poder é um processo que transcende mecanismos legais e constitui uma forma de poder estatal, engatado num aparelho de redes e relações que gera e legitima ações de identificação e classificação populacional no bojo de um imaginário de integração nacional, territorial e política.
} 
Vozes tuteladas, cidadanias esquivas: imagens discursivas de crianças e adolescentes... María del Carmen Castrillón Valderrutén

estão sob os cuidados de um "casal social". As crianças e os adolescentes de Cali pertencem a três instituições: a primeira abriga, num espaço comum, adolescentes do sexo feminino que sofreram exploração e abuso sexuais; a segunda também abriga, num espaço comum, crianças e adolescentes de sexo masculino com experiências diversas de vulneração social e familiar; a terceira instituição trabalha na modalidade de semi-internato, isto é, crianças e adolescentes permanecem na instituição durante oito horas diárias, particularmente, por estar em condições familiares de precariedade econômica, recebem assistência alimentar, educativa e recreativa. Igualmente, participaram crianças do programa de lares substitutos (hogares sustitutos) de uma sede do Instituto Colombiano de Bienestar Familiar (ICBF), entidade centralizada e estatal, encarregada da política social da infância e da família na Colômbia. À diferença das crianças das instituições anteriores, estas vivem nas próprias casas das mães sociais.

\section{Os híbridos perversos da tutela pública}

Embora os lugares de proteção tenham suas especificidades locais em termos das relações de intervenção construídas com as crianças e os adolescentes circulantes, no conjunto de experiências de institucionalização, há traços comuns no que diz respeito a ser criança ou adolescente sob a tutela do Estado, que deixam ver conflitos e ambivalências entre o ideal e o real, entre a condição de menoridade e a condição de cidadania, imprimindo discursividades angustiantes e liminares sobre suas trajetórias de vida. Tais trajetórias remetem diretamente a uma condição social da menoridade, cujo âmago sintetiza as vivências individuais de vulneração de direitos e as experiências de institucionalização legitimadas a partir de tal vulneração. A condição social da menoridade inscreve-se como fatalidade com traços perduráveis, pois se situam como centros estruturantes das identidades dessas crianças e adolescentes. Nesse sentido, alguns fragmentos discursivos expressos em palavras e desenhos são significativos ${ }^{4}$ :

M.C.: Que está acontecendo com as crianças e adolescentes aqui em Brasília?

${ }^{4}$ Para preservar o sigilo das crianças e adolescentes, os nomes usados neste trabalho são fictícios. 
Júlio: Eu acho triste é uma criança que nasce na rua e não tem direito à escola e a ter sonhos, e acaba se envolvendo com marginais virando o que eles são. Cheira colà e não tem direito de escolha, não tem uma família pra morar. Aí eul acho triste [...] acaba entrando nas drogas. Depois, quando desce mais, não tem mais chance nenhuma.

Mário: A maioria fica, assim, na rua, e cheira cola na rodoviária. Não tem uma família boa. As фutras passam dificuldade, com fome, falta de escola, dificuldade financeira.

Miguel: Adolescente pra mim é a fase mais difícil, porque os maiores de idade, alguns, põem na cabeça da gente isso e aquilo [...]. É muito dificil, alguns sobrevivem nessa fase e outros não [...] usar drogas, beber, fumar cheirar, fazer tudo [...] ou vai preso [...] ou mata alguém ou então rouba e termina morto [...] ou então vai pra cadeia.

(Júlio, 11 anos; Mário, 12 anos; Miguel, 13 anos, instituição que abriga meninos com experiênciąs de vida na rua de Brasília, Brasil)

M.C.: É legal ou não ser adolescente?

Rafaela: É chato.

M.C.: Por quê?

Rafaela: Porque nós somos um bando de rejeitados pelos adultos.

M.C.: Por quê? Como são rejeitados?

Regiane: Eles ficam, assim, chamando a gente de rebelde. Ficam dizendo que nós não valemos nada, ficam dizendo um monte de coisa.

Lucas: $E$, que os meninos pequenos se inspiram pela gente.

João: É, que nós somos exemplos pras crianças. Eles jogam na nossa cara. Falam um monte de coisa.

(Rafaela, 15 anos; Regiàne, 16 anos; Lucas, 15 anos; João, 16 anos, instituição de casas-lares de Brasília, Brasil)

Andréia: Eu acho que a| sociedade está fazendo [...] praticamente a rejeição, rejeitam muito as crianças.

M.C.: Como as rejeita?

Andréia: Exploram, porque eu tenho visto pais que botam para trabalhar os filhos muito pequenos [...] Assim, a gente vai tomando o caminho desde muito pequeno. Tem crianças desde muito pequenas na droga, tudo isso por causa da sociedade em que vivemos, a sociedade da intolerância, 
Vozes tuteladas, cidadanias esquivas: imagens discursivas de crianças e adolescentes... María del Carmen Castrillón Valderrutén

não tem compreensão, não tem carinho [...] o que sempre tem se recebido são socos, palavrões, maus tratos, insultos, corrupção, até estupro. Maria: Tem muitas formas de maus tratos na família. Uns são os estupros dos padrastos com as filhas. Minha mãe conseguiu um padrasto, então, já começa molestar a gente sexualmente, me estupra. Tem muitos casos em que a gente conta isso para a mãe, e a mãe não tá nem aí ou não acredita, diz que é para tirá-lo dela e que a gente gosta dele [...].

(Andréia, 17 anos; Maria, 14 anos, instituição de abrigo feminino para crianças e adolescentes que sofreram abuso e exploração sexual da cidade de Cali, Colômbia)

Igualmente, alguns desenhos expressam conflitos e ambivalências nas vivências de ser criança ou adolescente e nos ideais jurídicos que até hoje subsidiam uma condição moderna da infầncia.

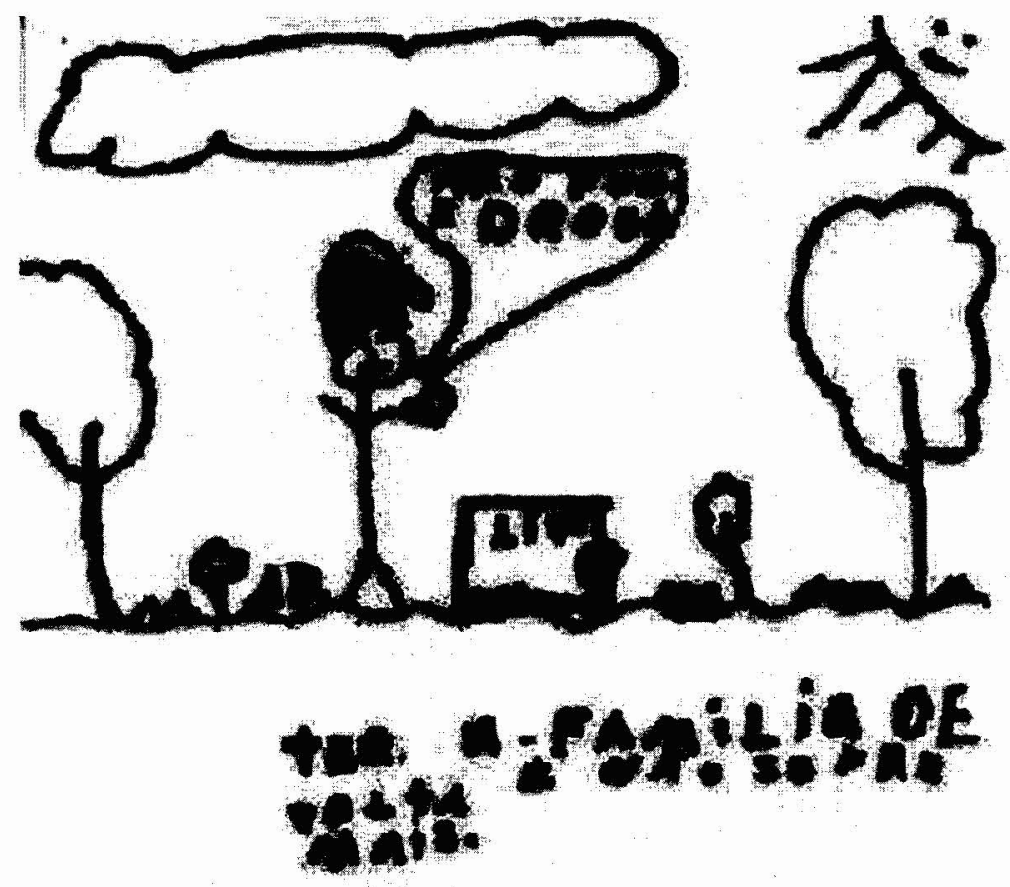

Figura 1

João, 10 anos, casas-lares de Brasília, desenho realizado a partir de uma atividade de completar frases. 
A frase do desenho é: "Os direitos mais importantes das crianças são...". Destacam-se nele: "Não fumar droga" e "Ter a família de volta, e não sofrer mais". Essa última frase é substantiva no contexto desse tipo de instituição, que trabalha com familias sociais ou substitutas.

Além de destacar a frase "La paz de Colombia" (a paz da Colômbia) que, de alguma forma, aglutina uma demanda mais geral no contexto político do país, o desenho acena para um evento de violência doméstica: "[...] que la ija (hija) resivió (recibió) con un abraso (abrazo) y el padre como venía borracho y le pego eso es maltrato" ([...] que a filha recebeu o pai com um abraço, e ele, como vinha bêbado, bateu nela. Isso são maus tratos).

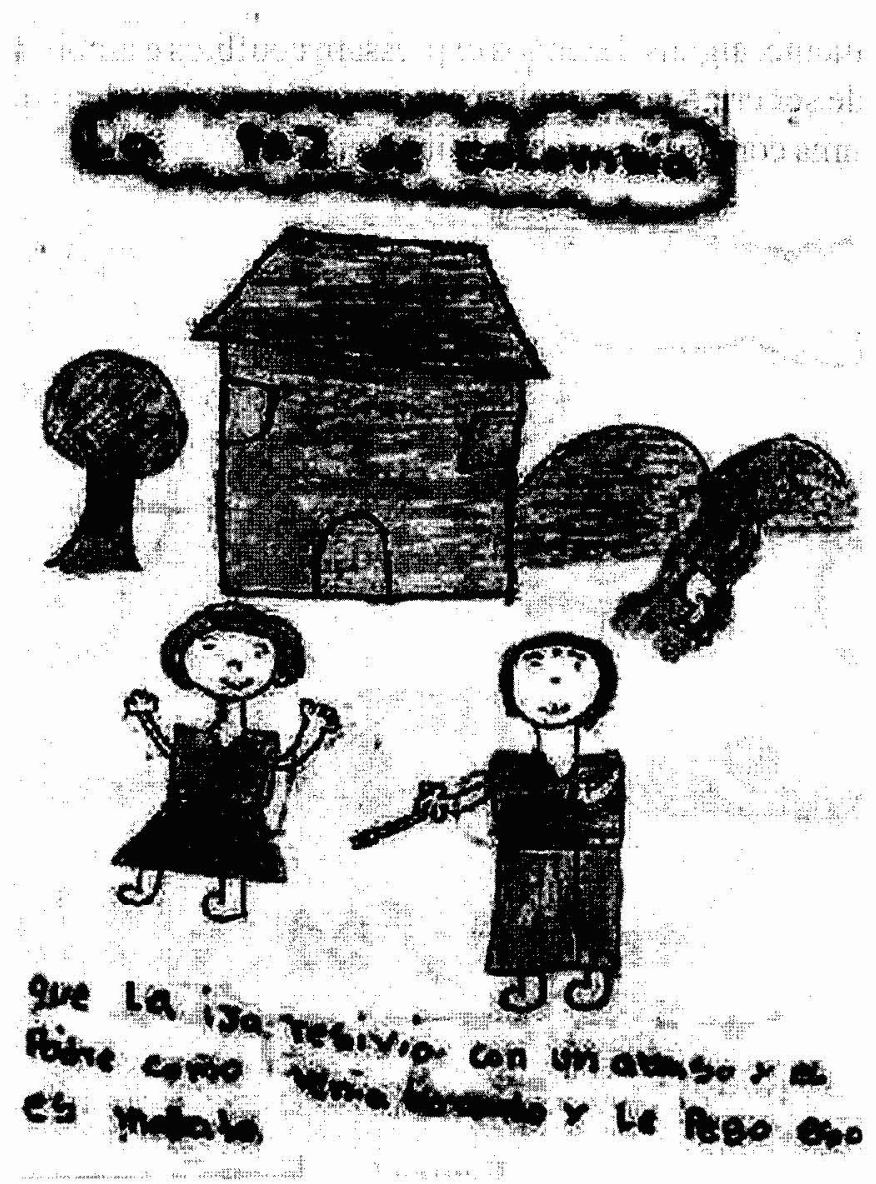

Figura 2

Luísa, 12 anos, instituição de semi-internato de Cali. 
Vozes tuteladas, cidadanias esquivas: imagens discursivas de crianças e adolescentes... Maria del Carmen Castrillón Valderrutén

Essas imagens em palavras e desenhos redimensionam as formas ideais dos lugares e sentimentos sociais destinados tanto a crianças e adolescentes quanto aos adultos na modernidade, estando os primeiros na condição de sujeitos em processos de formação física, mental e moral, e os segundos, encarregados de garantir esse desenvolvimento. Porém, as imagens que mostram essas crianças em particular são profundamente atravessadas por conflitos adultocêntricos, em que a violência institui suas próprias experiências de vida.

Nos desdobramentos desses contextos de violência, definem-se as classificações sociais e morais da intervenção tutelar. Essas classificações vêm acompanhadas de lugares institucionais, dentro dos quais crianças e adolescentes constroem inflexões trágicas que marcam suas identidades. Nas situações e condições vivenciadas por tais crianças e adolescentes, persiste a desconsideração de um direito fundamental: o da escolha, que, nas palavras de Júlio, da instituição de Brasília que abriga meninos com experiências de rua, determina um percurso difícil de transformar: "Nasce na rua e não tem direito à escola e a ter sonhos, e acaba se envolvendo com marginais, e acaba virando o que eles são. Cheira cola e não tem direito de escolha, não tem uma família pra morar".

Como circulantes de circuitos institucionais de proteção e assistência, a polifonia dessas vozes encontra-se interceptada pela coexistência conflitiva e ambígua dessas duas lógicas jurídicas de intervenção: uma lógica dos direitos cidadãos, que define crianças e adolescentes como sujeitos de direitos, na qual se projeta um reconhecimento digno de suas diferenças e igualdades; e uma lógica da menoridade, que define crianças e adolescentes como sujeitos de compaixão e repressão, legalizadas no denominado Paradigma da Situação Irregular, que determina uma criminalização e judicialização da pobreza e, particularmente, das famílias dos chamados "menores" circulantes da tutela do Estado.

Tais lógicas estariam atreladas a padrões reguladores de ordenamento sociocultural e moral, aliás, a processos civilizadores maiores-desde a ótica de Norbert Elias - que estruturam relações de poder, dominação e hierarquias atravessadas por princípios de classe, de gênero, de raça, de idade etc., legitimando e configurando cotidianamente as interações entre indivíduo e Estado. Em tal sentido, as vozes tuteladas das crianças e dos adolescentes constituem polifonias sociais, culturais e políticas que, ao estar atravessadas por essas lógicas, enunciam, desde o local, percursos civilizatórios de nossas relações com as intervenções estatais. Na perspectiva que Geertz (1994, p. 202) 
oferece acerca da relação entre fato e lei, estas vozes tuteladas também constroem "sensibilidades jurídicas", quer dizer, caracterizações e imaginários vernáculos sobre essa relação, sendo essas inflexões trágicas de suas vidas institucionalizadas metáforas acerca de princípios constitutivos da vida social. A lógica da menoridade e a lógica dos direitos cidadãos, como práticas discursivas, produzem efeitos reais nas trajetórias da vida dessas crianças e adolescentes, definindo processos e rituais específicos entre as categorias identitárias de "menor" e "criança ou adolescente".

Nesses amplos contextos de formação, as sensibilidades jurídicas dessas crianças e adolescentes e as lógicas de intervenção significadas podem ser entendidas no crivo da coexistência híbrida e contraditória daquilo que Soares (2000, p. 33-39) denomina modelos culturais de constituição das relações locais e nacionais ${ }^{5}$, que, embora façam referência ao âmbito brasileiro, pelas características sociopolíticas, podem ser ampliados a contextos como o colombiano: o relacional-hierárquico, que legitima concepções holistas das relações, subsidiadas por princípios de honra e moralidade, e o individualismo igualitário, que é marca paradigmática da modernidade ocidental e configurador de imaginários sobre os direitos, o Estado de Bemestar e as relações democráticas.

As trajetórias de vida dessas crianças e adolescentes evidenciariam, em algum sentido, essa coexistência que, nas afirmações de Machado (1985 e 2001), desdobram-se contraditoriamente: se, por um lado, o código relacional da honra configura relações positivas de reciprocidade, também constitui relações de violência e desigualdade (gênero, idade etc.); já o código individualista legitima os direitos cidadãos, mas também um individualismo soberbo e egoísta, descomprometido com a responsabilidade social e comunitária. Como se observa nos fragmentos e desenhos referenciados, crianças e adolescentes elaboram suas imagens discursivas daquilo que os tornou sujeitos de tutela pública e, nas interfaces dos direitos, explicitam dimensões perversas. Por exemplo, desde a lógica relacional da hon$\mathrm{ra}$, legitimam-se formas de violência no mundo da casa (abuso sexual pelo padrasto, maus tratos pelo pai, abandono etc.), enquanto não se reconhecem suas especificidades cidadãs, objetivando-se submetê-los às hierarquias de poder doméstico e, assim, preservar uma harmonia familiar.

${ }^{5}$ Soares constrói suas idéias em análises prévias fundamentais como as de Da Matta (1983 e 1985), que pensa as especificidades brasileiras à luz da relação entre igualdade e hierarquia e na perspectiva das consideraçð̃es teóricas de Luís Dumont e Marcel Mauss. 
Vozes tuteladas, cidadanias esquivas: imagens discursivas de crianças e adolescentes... Maria del Carmen Castrillón Valderrutén

Essa mesma lógica relacional da honra lhes traça o horizonte da rua, onde se defrontam não com uma lógica de um individualismo dos direitos cidadãos e de reconhecimento das alteridades, e sim com um individualismo narcisista de exclusão e negação social.

As inflexões trágicas expressadas nesses fragmentos discursivos se aprofundam à medida que os programas e serviços de proteção e assistência não revertem essa condição de sujeito tutelado, ao contrário, reproduzem-naainda em nome dos próprios direitos - numa circularidade institucional, que se sustenta na lógica da menoridade, da compaixão e repressão. Se, por um lado, tais crianças e adolescentes são protegidos e assistidos, Por outro, como outros marginais da harmonia social e familiar, são interditados e contidos, pois, finalmente, eles seriam portadores daquilo que Goffman chamou "quase humanidade", outorgando-lhes o estatuto de anormais. Uma vez interditados, procede-se ao exercício de uma ortopedia moral e de classe, para que essas crianças e adolescentes (quase humanos e anormais) se incluam na sociedade, mas sem esquecer que são menores, sem poder apagar as marcas de sua institucionalização: crianças e adolescentes terminam sendo um bando de rejeitados pelos adultos numa sociedade de intolerância.

A condição de menor que causa profundo mal-estar, porque atenta contra os valores tradicionais de ordenamento social e familiar - dali que se justifiquem práticas compassivas e repressivas -, também é experimentada pelas próprias crianças e adolescentes, por meio de sentimentos de culpa e vergonha. Numa busca por encontrar responsáveis por suas desafiliações, algumas crianças e adolescentes dizem:

M.C.: Alguém é responsável por haver tantas crianças na rua?

Vários adolescentes: Os pais.

M.C.: Por que os pais?

Wesley: Eu acho que é porque os pais não querem os filhos.

João: Não, a culpa não é dos pais. É porque os meninos, as crianças ficam fazendo as coisas e os pais não deixam, aí eles vão embora. Vão pra rua.

(Wesley, 12 anos; João, 11 anos, instituição que abriga meninos com experiências de vida nas ruas de Brasília, Brasil)

\footnotetext{
${ }^{6}$ Goffman $(1963$, p. 5) aponta que primeiramente se acredita, sobre as pessoas com algum estigma, em que elas ñ̃o são completamente humanas.
} 


\section{HümanAs}

Sônia: Para a gente ter chegado aqui numa instituição, é porque fez algo mau [...]. Por exemplo, aconteceu comigo, quando a gente foge de casa, a gente já sabe, a gente sabe que é o que a gente quer.

(Sônia, 16 anos, instituição de abrigo feminino para crianças e adolescentes que sofreram abuso e exploração sexual da cidade de Cali, Colômbia)

M.C.: Por que os adultos agem desse jeito tão negativo com as crianças? Harold: Porque as crianças se comportam mal, não obedecem se pedem um favor e a gente não faz ou diz palavrões aos mais velhos. Então, por isso, batem nelas ou as abandonam.

(Harold, 10 anos, instituição de abrigo masculino de Cali, Colômbia)

Essas culpas obedecem a uma moralidade que individualiza as dimensões sociais das relações, negando, desse modo, as bases contextuais da exclusão, da desafiliação e da institucionalização, de modo que crianças e adolescentes tornam-se responsáveis por excelência por sua situação e condição: "Para a gente ter chegado aqui numa instituição, é porque fez algo mau". Igualmente, esses sentimentos associam-se a uma moralidade que defende as hierarquias domésticas, cuja desobediência a elas implica algum tipo de punição: "Porque as crianças se comportam mal, não obedecem [...] ou dizem palavrões aos mais velhos. Então, por isso, batem nelas ou as abandonam".

Eventos como os seguintes são expressivos de sentimentos de uma vergonha que parece marcar-lhes a predeterminação da tutela pública.

\section{Evento 1}

Luís de 10 anos, da instituição de abrigo masculino de Cali (Colômbia), é uma das muitas crianças que não conhecem outra vida além da oferecida pelos programas de proteção da cidade, pois, desde que nasceu, circulou por instituições de abrigamento, na espera por ser adotado. Numa de minhas idas à instituição, Luís - com quem já havia conversado várias vezes - se aproximou de mim, pegou minha mão e me separou das outras pessoas com quem eu estava no momento (a psicóloga da instituição e outras crianças) 
Vozes tuteladas, cidadanias esquivas: imagens discursivas de crianças e adolescentes... María del Carmen Castrillón Valderrutén

para me dizer discretamente: “Te conto um segredo. Sabe, eu não tenho família". O que eu poderia dizer a Luís? Aquelas frases cínicas como "Fique tranqüilo, vai ter uma família que te adote" ou "A instituição é como uma família". É um segredo vergonhoso e conhecido, ao mesmo tempo em que o torna alvo de escárnio por parte de seus companheiros de instituição, que o chamam de "órfão" e "abandonado". Foi uma vergonha ainda mais explícita quando a psicóloga, em suas "boas intenções", levou Luís para passar um fim de semana em sua casa, para que, assim, ele se sentisse como em família, pois tinha muita pena dele.

\section{Evento 2}

Três irmãos, Ana de nove anos, Paula de 10 e Wilson de sete, vivem na instituição de casas-lares de Brasília. Eles, à diferença de Luís, têm mãe, que os visita de vez em quando, mas cada visita, antes de ser um momento prazeroso, torna-se desagradável e vergonhosa para essas crianças, já que a mãe, além de morar na rua, tem transtornos mentais. Numa visita, Ana, Paula e Wilson estavam com sua mãe na praça central da instituição, tentando, como outras vezes, fazer desse encontro um momento menos constrangedor. Um deles perguntou para a mãe com tom de recriminação e no meio das frases "soltas" que ela expressa: "Por que veio?". Essa pergunta, que também parece dizer "não venha mais", confirma os escárnios discretos e explícitos sobre a fatalidade de ter uma mãe, mas, ao mesmo tempo, tê-la fora dos padrões da filiação familiar legitimados socialmente. É uma tragédia aprofundada, quando as crianças comparam essa mãe, que persiste no vínculo, com aquela que cuida deles na instituição, a mãe social. Também é trágico quando a assistente social argumenta que, mesmo não querendo, as crianças têm de aprender a amar sua mãe, apesar de ela estar "louca".

\section{Comentários}

O primeiro evento expressa condição de carência (ser órfão e não ser adotado) e o segundo, condição de excessos (ter mãe, mas com problemas mentais e ser cuidado por outra que não é $a$ biológica). Ambas as condições representam limites da desonra social e as rupturas com uma lógica harmônica da sociedade, em que o único direito possível é o direito à família, 
mas a uma família orientada para projetar um indivíduo que dificilmente conseguirá se libertar das armadilhas da consangüinidade e das hierarquias. As sensibilidades jurídicas dessas crianças e adolescentes, seus modos de ver os percursos do justo e do injusto de suas vidas, são geradas em espaços institucionais (casas-lares, instituições de abrigo, famílias substitutas etc.) que carregam e reproduzem o estigma da desafiliação social, fundamentalmente, aquele que diz respeito às relações familiares que não se alinham ao modelo moderno nuclear e consangüíneo, bastante próximo da figura cristã da "sagrada família" (CASTRILLÓN, 2007, p. 118-123).

\section{Rituais institucionais}

Perante essas imagens expressivas da eficácia da lógica da menoridade, a passagem pelos mundos institucionais (dos abrigos, das casas-lares, das familias substitutas), em princípio transitória, mas na verdade permanente, é fundamentalmente circular, já que os percursos construídos pelas crianças e adolescentes em questão têm como ponto de partida e chegada um mesmo eixo conceitual e jurídico dessa infância e adolescência: a lógica da menoridade. Outras discursividades ligadas a uma lógica dos direitos cidadãos (reconhecimento das diferenças e igualdades em condições de dignidade) ainda não se incorporam nos ensamblagens institucionais desses circuitos tutelares, ainda não há espaços ideológicos para se instituir sua eficácia. Com dificuldade, essa lógica começa a gerir espaços discursivos, mediante os esforços de organizações, grupos e indivíduos da sociedade civil, que tentam ressignificar as práticas de proteção e assistência nos horizontes semânticos dos direitos humanos.

Pensar rituais de passagem que apontem para um processo de destutelarização pública significaria transitar em um caminho de descontrução subjetiva da condição da menoridade. Porém, entendendo que os rituais de passagem são, de acordo a Van Gennep (1978), momentos da vida humana nos quais se efetuam transformações profundas na busca pela apropriação de um status ontológico diferente, percebe-se que os percursos institucionais da vida permitem construir experiências distantes de um projeto de criança cidadã ou adolescente cidadão, pois os rituais vivenciados inscrevem-se na circularidade da menoridade. A partir dessa circularidade, essas crianças e adolescentes percorrem seus itinerários de transformação subjetiva: 
Vozes tuteladas, cidadanias esquivas: imagens discursivas de crianças e adolescentes... María del Carmen Castrillón Valderrutén

de abandonados, órfãos, explorados sexualmente, infratores etc. $a$ menores em condição de tutela pública. Amenoridade vem a ser uma marca prolongada no tempo, cujo princípio de ressocialização é justamente a reprodução de um sujeito social afirmado na máxima expressão de sua exclusão como outro marginal e negado como outro cidadão.

Assim sendo, rituais de circularidade ${ }^{7}$ são construídos em duas temporalidades, no interior institucional da menoridade: A primeira temporalidade diz respeito à circulação dessas crianças e adolescentes, por um conjunto de experiências de institucionalização, em diversas instituições ou programas no cerne do status jurídico de menor de idade (geralmente até os 18 anos). Muitas crianças e adolescentes de Brasília já tinham passado, por exemplo, pelo Centro de Abrigamento Reencontro (antigo Centro de Recepção e Triagem - CEAR) e por outras instituições, antes de chegar aos lugares que esta pesquisa considerou. Algumas crianças dos lares substitutos (Programa de Famílias Substitutas ou mães substitutas) do Centro Zonal do ICBF de Cali já haviam estado com outras famílias ou em instituições de abrigo.

A segunda temporalidade refere-se a uma vida pós-institucional, quando essas crianças e adolescentes ficam de fora do status jurídico-etário da proteção, mas continuam a gravitar sobre o eixo da menoridade. Diminuídas suas possibilidades de transcender as marcas sociais e morais dessa condição, a passagem para uma vida adulta igualmente termina sendo um caminho instrumentalizado, na consecução da maioria de idade juridicamente reconhecida e, com isso, de autonomia. Uma vez que atingem 18 anos (com exceções, pode-se chegar aos 21 anos, como consta nas legislações), retirase-lhes a tutela pública, sem lhes garantir obviamente a socialização com uma vida adulta de inclusão, baseada numa lógica de direitos e cidadania.

\footnotetext{
${ }^{7}$ A questão da circulação de crianças e adolescentes tem sido estudada por autores como Fonseca (1993 e 1995) e Gregori (2000). Os trabalhos de Fonseca, a partir de uma pesquisa sobre famílias de baixa renda em Porto Alegre (Brasil), destacam como, em mais da metade dos casos, as mulheres tinham cedido seus filhos para ser criados por outros - geralmente parentes -, configurando, segundo a autora, uma alternativa de organização de vínculos familiares, característica de uma cultura popular urbana, não relacionada a uma crise de valores vinculada a essa situação de pobreza. Gregori, em sua pesquisa sobre experiências sociais e institucionais de crianças e adolescentes habitantes de rua em São Paulo, explica a circulação como uma das características significativas de suas vidas, apontando os itinerários relacionais: a circulação por instituições que lhes dão apoio, por instituições de "triagem" e pelas rotas da casa e a rua. A circulação à qual faço referência traça outras passagens, em que a intervenção institucional sempre está presente, instalando-se como o eixo fundante dos itinerários relacionais. É provável que as crianças e os adolescentes referidos neste trabalho tenham construido experiências de vida nessas formas de circulação e que o destino da tutela pública seja uma resposta trágica aos paradoxos advindos desses itinerários familiares, sociais e culturais.
} 


\section{HUMANAS}

A história comum dessas crianças e adolescentes é a história de certa continuidade no signo da menoridade, governada por rotas similares àquelas que lhes abriram as portas para ingressar nesses modernos infernos de ressocialização. Uma dessas histórias é a de Carlos, que, na época da pesquisa, como 27 anos, ainda morava com a mãe substituta, sendo então o "irmão social" mais velho de uma das crianças do programa de lares substitutos participante desta pesquisa. Com duas filhas, sem emprego e sem qualificação profissional, pensava em trabalhar em negócios ilicitos, ganhando dinheiro na hora como "sicario" (assassino de aluguel), com um grupo do bairro onde vivia. Disse também que, uma vez concluída a permanência no programa de proteção, só ficou a generosidade da mãe social que cuidou dele desde os 11 anos, deixando que morasse em sua casa, pois nunca teve outras filiações ou redes sociais e institucionais alternativas que the oferecessem subsídios para fazer passagem digna para a vida adulta.

Nesse sentido, tomam corpo alguns jogos de encenamento de cidadania que se projetam como pontes para atingir uma vida adulta pós-institucional e que se condensam no tradicional lema de "elevar a auto-estima". Esses jogos se materializam, por exemplo, em ações de fortalecimento psicossocial para a inclusão na sociedade (atenção psicológica individual e grupal, mas geralmente com orientação comportamental) e em atividades de capacitação para o trabalho (cursos e oficinas profissionalizantes). Mas, dentro das configurações ideológicas do Estado de Bem-estar (que em nossas histórias locais configura-se geralmente como um Estado filantrópico) também se busca dignificar a pobreza dos outros, nesse caso das crianças e adolescentes circulantes dos programas de proteção, ainda em nome dos direitos cidadãos. Elevar a auto-estima implica fazer um trabalho (terapêutico) de adaptação das subjetividades das crianças e adolescentes à moral institucional na qual circulam, sendo essa um reduto de uma moral mais abrangente, que busca preservar a ordem e as hierarquias familiares, de classe, de gênero, de idade, destinando aos pobres inclusões residuais na cidadania. ${ }^{8}$

\footnotetext{
${ }^{8}$ A idéia de "carreira moral" desenvolvida por Goffman (1999, p. 111-112), no estudo sobre instituições totais é pertinente para se compreender os modos de subjetivação dos indivíduos nesses espaços. Segundo o autor, o conceito de carreira moral diz respeito às mudanças do eu no interior das instituições, caracteriza, ao mesmo tempo, uma interação ambivalente entre o público e o privado, entre os assuntos "íntimos e preciosos" - como a imagem do eu e a segurança sentida - $\mathrm{e}$ a posição oficial, as relações jurídicas e o estilo de vida. A carreira moral projetada dentro dos programas e serviços de proteção para crianças e adolescentes busca reduzir ou encobrir as imagens subjetivas do eu - que condensa experiências híbridas extra e intra-institucionais - nas relações e lugares jurídicos oficiais, demarcadores de padrões institucionais de estilos de vida - orientados a modelar sujeitos e comportamentos jurídicos interditados e tutelados.
} 
Embora essas crianças e adolescentes encontrem-se incorporados nas atividades de educação formal pública (em processos de escolarização regular), as atividades de adestramento e capacitação para o trabalho parecem ter ampla legitimidade nos circuitos institucionais de tutela pública. Neles existe preocupação com preparar crianças e adolescentes para o mundo do trabalho, para o aprendizado de um ofício, por meio de cursos e oficinas técnicas - padaria, artesanato, cabeleireiro, confecção de cartões, roupas, bonecas etc. Parece então que o presente e o futuro dessas crianças e adolescentes em tutela pública circunscrevem-se numa formação mínima que lhes outorgue inclusão mínima para sobreviver fora das fronteiras institucionais.

Embora inseridos no mundo escolar e abrangidos legislativamente pelo "direito à educação" (Código de la Infancia y la Adolescência, Colômbia, Art. 28; ECA, Brasil, Cap. IV, Art. 53), essas crianças e adolescentes terminam construindo experiências educativas reduzidas a instrumentalização escolar e esvaziadas de recursos simbólicos eficazes, para se apropriar de uma dinâmica de mobilidade social, na qual possam realizar a passagem real de menor a criança cidadã ou adolescente cidadão. Essa preocupação moral para incluir as crianças no mundo do trabalho mínimo está fortemente relacionada com pressupostos ideológicos (morais e de classe) que alicerçam os circuitos institucionais de proteção e assistência e que, em defesa do social, fortalecem a idéia - ecoada nas vozes de grande parte dos técnicos e operadores do programas de proteção - de que, aprendendo algum oficio, dignificam sua pobreza.

Por trás desses princípios ideológicos há também uma questão instituinte das relações sociais que demarca e identifica igualdades e diferenças. É a dicotomia entre estabelecidos e marginais e seus subseqüentes desdobramentos na construção de estigmatizações, advindos de relações de poder que medeiam a interdependência entre essas duas categorias de ordenamento social ${ }^{9}$. Mas, situando-se essa dicotomia nas experiências de vida institucional das crianças e adolescentes em foco, a definição de "rito de instituição" apresentada por Bourdieu (1985, p. 78-80) fornece elementos significativos para se compreender a eficácia dos rituais de circularidade no interior da menoridade, enquanto elenca justamente o efeito de "separação".

\footnotetext{
'Um estudo interessante sobre essa dicotomia é o de Elias e Scotson (2000), que analisam as relações entre estabelecidos e outsiders, numa pequena cidade inglesa. Os autores explicam as configurações de poder que permitem que um "grupo estabelecido" possa estigmatizar outro grupo de tal forma que o situe plenamente como outsider, como marginal. Nesse caso, os outsiders seriam portadores de comportamentos "anômicos" e inferiores, como a "desintegração" ou a "delinquiência".
} 


\section{HÜMANAS}

Para o autor, os ritos de instituição tendem a consagrar ou legitimar um limite arbitrário e, assim, efetuar ritualmente uma separação para instituir uma identidade, impor um nome, uma essência social.

Instituir uma essência ou uma competência significa um direito de ser que, ao mesmo tempo, é um dever ser, aliás, é significar alguém de forma particular, para que se conduza a partir dessa significação: o indicativo seria então um imperativo. Essa explicação de Bourdieu destaca que não só se trata de uma distinção entre aqueles que receberam uma "identidade", um "nome" ou "essência social" e os que ainda não a receberam, por sua condição particular, pois também constitui uma divisão entre aqueles que são socialmente dignos de receber uma marca distintiva e os que se encontram completamente excluídos dessa possibilidade.

Os ritos de circularidade construídos por essas crianças e adolescentes seriam uma forma particular desses ritos de instituição, pois eles consagram uma separação entre menores e crianças e adolescentes, fazendo com que os primeiros (menores) nunca consigam ter a marca distintiva - porque desonram valores máximos da ordem familiar e social - que lhes outorgue um nome, uma identidade - ser criança, adolescente - e uma essência socialser cidadãos na igualdade e na diferença. Consagra-se então uma separação que institui uma temporalidade contínua da menoridade, que se estende e fortifica junto à emergência de práticas políticas profundamente intolerantes em torno da relação naturalizada entre pobreza e perigo, ou seja, entre: raça, pobreza e perigo; classe, pobreza e perigo; idade, pobreza e perigo; gênero, pobreza e perigo; e assim por diante.

\section{A permanência da menoridade e as cidadanias esquivas: algumas conclusões}

No panorama desolador dado pela permanência de uma lógica compassiva e repressiva, nas práticas de intervenção tutelar e nas vozes das crianças e adolescentes, uma lógica dos direitos parece etérea. Mas, no cerne dessa permanência, nas vozes, há traços discursivos profundamente significativos, que fraturam essa temporalidade contínua da menoridade, fazendo contrapeso com lugares e sentimentos de negação e colonização sociomoral, instituídos pelas intervenções protetivas. Dentro da circularidade pela menoridade que os identifica, emergem interpelações discursivas que explicitam uma condição crítica e reflexiva dessas crianças e adolescentes, já perfilada nos fragmentos e desenhos anteriormente referenciados. 
Vozes tuteladas, cidadanias esquivas: imagens discursivas de crianças e adolescentes... María del Carmen Castrillón Valderrutén

Frente a essa condição social da menoridade - configurada por suas próprias trajetórias de vida em que o denominador comum é a vulneração explícita dos direitos fundamentais - as crianças e os adolescentes participantes desta pesquisa constroem sensibilidades jurídicas que significam o caráter do social e o papel da intervenção do público na proteção e assistência a esses grupos sociais, a essas "idades da vida". Assim, referenciam um espectro de ações que fazem referência tanto a demandas assistencialistas e filantrópicas como a interpelações dos direitos que lhes são singulares, situando as contradições estruturantes das políticas sociais para essas crianças e adolescentes, quer dizer, determinando se sua relação com o social dá-se na base de um projeto de menor cidadão ou de um sujeito de direitos tutelados.

Quando emergem esses traços, realizando rupturas discursivas na temporalidade constante da menoridade, apresentam-se situações de liminaridade jurídica na condição institucionalizada dessas crianças e adolescentes, pois, ao enunciar significações sobre seus direitos, desprendem-se por um momento dessa temporalidade - como estado, desde a perspectiva de Turner (1988) - ficando discursivamente numa posição transicional, separados de seu status de menor em tutela pública. Nesse caso, essa liminaridade dificilmente fará ritos eficazes de passagem para outro status que os conduza à construção do reconhecimento cidadão do ser criança e adolescente ${ }^{10}$.Ao contrário, pela força ideológica dessa temporalidade, as crianças e os adolescentes em questão terminam retraídos ao status social e moral oferecido pela menoridade.

Ao falar dos direitos, surgiram considerações como as seguintes, no diálogo com os adolescentes e crianças:

M.C.: Vocês já escutaram falar dos direitos das crianças e dos adolescentes?

Lucas: Mais ou menos. Eu sei que tem que ter uma boa escola, família, ter mãe e pai com bom emprego. Que não seja violentada, assim, corrigir, mas não violenta. Só.

Wilson: $O$ direito das crianças é brincar.

\footnotetext{
${ }^{10}$ Uma condição de entretempos discursivos é exprimida na própria dinâmica legislativa atual da América Latina, referente à proteção e assistência da infầncia e da adolescência, sendo caracterizada nas relações e ações que o ECA tem constituído com os circuitos institucionais de intervenção, durante essas quase duas décadas de aprovação.
} 


\section{HUMANAS}

M.C.: Que outros direitos têm?

André: É também saber o que é certo e o que é errado.

Wilson: É obedecer.

Leandro: Eu acho que um dos direitos de uma criança é brincar, aprender algumas coisas [...] e também um direito nosso é obedecer aos mais velhos. O nosso direito também é de estudar numa escola boa. Eu gosto muito de estudar numa escola.

M.C.: E quais são os deveres dos adultos com as crianças e adolescentes? Diogo: É que os adultos têm que obedecer às crianças e as crianças obedecer aos adultos. Assim, as crianças têm que respeitar os adultos, e não xingar o adulto.

Antônio: Os adultos têm que cuidar das crianças, não deixar elas com arma, não deixar elas fumar maconha, não deixar elas sair pra roubar dinheiro, pra pedir dinheiro, pra fumar e nem as crianças deixar os adultos. As crianças têm que respeitar o pai, a mãe, o avô, a bisavó.

(Lucas, 11 anos; Wilson, 10 anos; André, 11 anos; Leandro, 12 anos; Diogo, 11 anos; Antônio, 12 anos, instituição que abriga meninos com experiências de vida na rua de Brasília, Brasil)

M.C.: Vocês conhecem o estatuto da criança e do adolescente?

Tainá: Eu já vi. Não sei se é isso. Direitos. Direito de estudar. Direito de ter uma família. Direito de sobreviver. Direito de brincar. Direito de ficar de castigo.

M.C.: O que está acontecendo com esses direitos?

Tainá: Não está dando certo.

M.C.: Como deveria ser, por exemplo, a sociedade brasileira para que seus direitos sejam cumpridos?

Vânia: Não ter violência. Sempre ter paz entre a gente e educação.

Tiago: Não ter pobreza. Ter paz na sociedade. Ter harmonia, o amor e paz, educação, respeito.

Wilson: [...] Tem muitas pessoas que não tem o que comer, e aí eles não querem mais e jogam fora, e muitas pessoas que precisam e aí que pedem, eles falam assim, "não, não tem, não". Tem essas questões todas [...]. Elizete: Dividir com os outros. Dividir tudo.

(Tainá, 15 anos; Vânia, 16 anos; Tiago, 14 anos; Wilson, 14 anos, instituição de casas-lares de Brasília, Brasil) 
Vozes tuteladas, cidadanias esquivas: imagens discursivas de crianças e adolescentes... María del Carmen Castrillón Valderrutén

M.C.: Tem escutado alguma coisa sobre os direitos da criança e do adolescente?

Mónica: Direito de dormir, direito de sonhar, direito de brincar.

Matilde: Direito de ir para rua.

Fabián: Direito de pensar as coisas.

Mónica: Direito de compartilhar as coisas.

Fabián: Direito a ter amor. A gente ter direito de fazer a vida como quer. Ter paz.

Mónica: A ter saúde.

M.C.: Esses direitos para que servem?

Fabián: Para que as crianças possam se sentir bem, para não se sentir sozinhas.

Mónica: Para viver [...]

Matilde: Em paz.

Fabián: Faltou dizer uma coisa, ir para igreja, a gente vai à igreja pedir ao Senhor que nos mantenha com vida.

(Mónica, 8 anos; Matilde, 8 anos; Fabián, 11 anos, lares substitutos do ICBF, Cali, Colômbia)

M.C.: De que estão precisando as crianças e os adolescentes?

Pedro: Da proteção de todo mundo.

M.C.: Como deveria ser essa proteção?

Pedro: Não fazendo mal às crianças.

M.C.: Como faz a gente para isso?

Andrés: Viver tranqüilos, ter mais responsabilidade, mais carinho e afeto. M.C.: De que precisam as crianças para que possam viver felizes?

Alberto: Hoje em dia, uma criança precisa de muitas coisas. Precisa de amor, precisa de compreensão dos maiores, precisa que a escutem, porque a maioria dos adultos não se importa com o que a gente pensa, o que a gente sente, e por isso, às vezes, a gente não vive feliz, e vive mal. Também estudar, porque a maioria das crianças ficou sem estudar.

(Pedro, 11 anos; Andrés, 12 anos, Instituição de abrigo masculino de Cali, Colômbia) 
Essas interpelações, expressivas das sensibilidades jurídicas dessas crianças e adolescentes, deixam ver espaços de desnaturalização e estranhamento de seus lugares identitários de menores, de outsiders em contextos de exclusão social e institucional. Eles significam os direitos em necessidades, demandas e deveres, definitórios de valores afetivos, éticos e morais, que atravessam sua condição de crianças e adolescentes em processos singulares de formação e autonomia subjetiva, nos quais os adultos tornam-se responsáveis por seu reconhecimento. Mas esses modos de significar sua relação com o público pela via dos direitos vêm inscritos numa dimensão hierárquica das relações familiares e sociais: Antônio, por exemplo, diz que: "Os adultos têm que cuidar das crianças, não deixar elas com arma, não deixar elas fumar maconha [...] nem as crianças deixar os adultos. As crianças têm que respeitar o pai, a mãe, o avô, a bisavó". Tainá aponta os direitos assim: "Direito de estudar. Direito de ter uma família. Direito de sobreviver. Direito de brincar. Direito de ficar de castigo". Fabián salienta, dentro dos direitos, não só o "direito de pensar as coisas", "ter amor", "a gente ter direito de fazer a vida como quer", mas também o direito de "ir para igreja [...] pedir ao Senhor que nos mantenha com vida".

No entanto, essa imbricação de uma discursividade de direitos cidadãos numa dimensão hierárquica de relações sociais - como rasgo particular de nossas formas locais de recomposição de ideologias modernas sobre o Estado de Bem-estar e suas configurações democráticas - não oblitera o fato mesmo da expressão de uma polifonia nos limites institucionais da tutela pública, que se subsidia pela circulação das discursividades oficiais em torno do paradigma da proteção integral, como correlato dos direitos humanos da infância e de adolescência na modernidade. Existe nessas crianças preocupação com integrar o social a princípios que garantam transformações eficazes em suas próprias vidas, possibilitando-lhes transcender a precariedade e fragilidade de seus vínculos socioeconômicos e afetivos. As sensibilidades jurídicas são então construídas por essas crianças e adolescentes, a partir das inflexões emergidas nas intervenções de proteção e assistência, que conjugam contraditoriamente a tutela e o contrato.

O desafio é que essa mesma modernidade, que vem designando a essas crianças e adolescentes lugares menorizados de vida social, consagre-lhes proteção integral desinstitucionalizada e que esses traços discursivos sobre os direitos sejam o centro de ancoragem para constituir subjetividades baseadas no reconhecimento cidadão da igualdade e da diferença, 
Vozes tuteladas, cidadanias esquivas: imagens discursivas de crianças e adolescentes... María del Carmen Castrillón Valderrutén

para que, assim, deixem de ser sujeitos expiatórios sobre os quais se legitimam os experts do "panoptismo" da menoridade.

\section{Referências bibliográficas}

ARIÈS, P. História social da criança e da familia. Rio de Janeiro: Zahar, 1987.

BAKHTIN, M. Problemas da poética de Dostoiévski. Rio de Janeiro: Forense, 1981.

BRANDÃO, C. R. A criança que cria: conhecer seu mundo. In: A educação como cultura. São Paulo: Brasiliense, 1985.

BOURDIEU, P. Economía de los intercambios lingüísticos. Madrid: Akal, 1985.

BRASIL. CONGRESSO NACIONAL. Estatuto da criança e do adolescente (ECA). Lei 8.069, 1990.

CASTRILLÓN, V. M. C. ¿Menores ciudadanos o sujetos de derechos tutelados? Discursividades institucionales sobre de los derechos de la niñez y la adolescencia en Brasil y Colombia. Revista Campos - Programa de Pós-graduação em Antropologia, Universidade Federal de Paraná, Brasil, 2009 , no prelo.

CASTRILLÓN, V. M. C. Discursos institucionales sobre la familia en Brasil y Colombia: ¿biologizar/nuclearizar o reconocer su diversidad?’. Revista latinoamericana de ciencias sociales, niñez y juventud - Universidad de Manizales, Colombia, v.5, n.1, p.83-124, enero-junio, 2007.

CASTRILLÓN, V. M. C. ¿Menores ciudadanos o sujetos de derechos tutelados? Reflexiones sobre las políticas y programas para la infancia y la adolescencia en Brasil y Colombia. 202f. Tese (Doutorado em Antropología Social) - Centro de Pesquisa e Pós-graduação sobre as Américas (CEPPAC), Universidade de Brasília, 2005.

CASTRO, L. R. (Org.). Crianças e jovens na construção da cultura. Rio de Janeiro: NAU-FAPERJ, 2001. 


\section{HÜMANAS}

COHN, C. Antropologia da criança. Rio de Janeiro: Jorge Zahar, 2005.

COLOMBIA. CONGRESO DE LA REPÚBLICA. Código de la Infancia y la Adolescencia. Ley 1098 del 2006, 2007.

CORSARO, W.; EDER, D. Children's peer cultures. Annual Review of Sociology, v.16, p.197-220, 1990.

CORSARO, W. The sociology of childhood. Thousand Oaks: Pine Forge Press, 1997.

DAMATTA, R. A casa e a rua: espaço, cidadania, mulher e morte no Brasil. São Paulo: Brasiliense, 1985.

DA MATTA, R. Carnavais, malandros e heróis: para uma sociologia do dilema brasileiro. 4.ed. Rio de Janeiro: Zahar, 1983.

DEMAUSE, L. Historia de la infancia. Madrid: Alianza Universidad, 1982.

DONZELOT, J. A polícia das famílias. Rio de Janeiro: Graal/Biblioteca de Filosofia e História das Ciências, 1986.

ELIAS, N. La civilización de los padres y otros ensayos. Bogotá: Grupo Editorial Norma, EUN-Editorial Universidad Nacional, 1998.

ELIAS, N.; SCOTSON, J. Os estabelecidos e os "outsiders": sociologia das relações de poder a partir de uma pequena comunidade. Rio de Janeiro: Jorge Zahar, 2000.

FONSECA, C. Caminhos da adoção. São Paulo: Cortez, 1995.

FONSECA, C. Criança, família e desigualdade social no Brasil. In: A criança no Brasil hoje: desafios para o terceiro milênio. RIZZINI, I. (Org.). Rio de Janeiro: Editora Universitária Santa Úrsula, 1993.

GEERTZ, C. Available light. New Jersey: Princeton University Press, 2000.

GEERTZ, C. Conocimiento local: ensayos sobre la interpretación de las culturas. Barcelona: Ediciones Piados, 1994.

GOFFMAN, E. Manicômios, prisões e conventos. São Paulo: Perspectiva, 1999. 
Vozes tuteladas, cidadanias esquivas: imagens discursivas de crianças e adolescentes...

María del Carmen Castrillón Valderrutén

GOFFMAN, E. Stigma. Notes on the management of spoiled identity. New Jersey: Prentice-Hall, Englewood Cliffs, 1963.

GRAUE, E. e WALSH, D. Investigação etnográfica com crianças: teorias, métodos e ética. Lisboa: Fundação Calouste Gulbenkian, 2003.

GREGORI, M. F. Viração. Experiências de meninos nas ruas. São Paulo: Companhia das Letras, 2000.

JAMES, A.; JENKS, Ch. e PROUT, A. Theorizing childhood. Cambridge: Polity Press, 1998.

JAVEAU, C. Criança, infância(s), crianças: que objetivo dar a uma ciência social da infância? Revista Educação e Sociedade, São Paulo, v. 91(26), p.379-389, 2005.

LIMA, A. C. Um grande cerco de paz: poder tutelar, indianidade e formação do Estado no Brasil. Petrópolis: Vozes, 1995.

LOPES DA SILVA, A.; MACEDO, A. V. L. S. e NUNES, Â. (Orgs.). Crianças indigenas: ensaios antropológicos. São Paulo: Global. Coleção Antropologia e Educação, 2002.

MACHADO, L. Z Famílias e individualismo: tendências contemporâneas no Brasil. Departamento de Antropologia, Universidade de Brasília, 2001. Série Antropologia.

MACHADO, L. Z. Família, honra e individualismo. In: Anuário antropológico. Rio de Janeiro: Paz e Terra, 1985.

MEAD, M. Adolescencia, sexo y cultura en Samoa. Buenos Aires: Planeta Agostini-Paidós, 1993.

MEAD, M. Sexo y temperamento. São Paulo: Perspectiva, 1978.

MEAD, M. Educación y cultura en Nueva Guinea. Buenos Aires: Paidós, 1977.

ORGANIZAÇÃO DAS NAÇÕES UNIDAS - ONU. Assembléia Geral das Nações Unidas. Convenção sobre os Direitos da Criança, 1989. Disponível em: http://www.unicef.org. Acesso em: 15 ener. 2009. 


\section{UMANAS}

SARMENTO, M. Culturas da infância. Texto produzido no âmbito do projeto "As marcas dos tempos: a interculturalidade nas culturas da infância”. Lisboa, 2002. Disponível em: $<$ http://www.Iec.Uminho.Pt/Cedic/Textosdetrabalho/Imacultinfancia.Doc >. Acesso em: 11 abr. 2003.

SOARES, L. E. Uma interpretação do Brasil para interpretar a violência. In: PEREIRA, C. A. et al. (Orgs.). Linguagens da violência. Rio de Janeiro: Rocco, 2000.

TURNER, V. El proceso ritual. Madrid: Taurus, 1988.

VAN GENNEP, A. Os ritos de passagem. Petrópolis: Vozes, 1978.

VIANNA, A. O mal que se adivinha: polícia e menoridade no Rio de Janeiro, 1910-1920. Rio de Janeiro: Arquivo Nacional, 1999. 